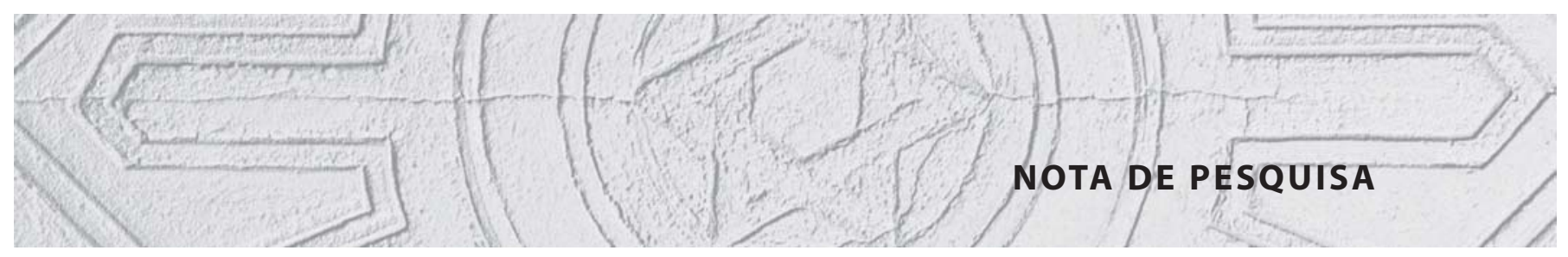

\title{
Educação sanitária e saúde pública em Minas Gerais na primeira metade do século $\mathrm{XX}$
}

\section{Sanitary education and public health in the State of Minas Gerais in the first half of the twentieth century}

Jean Luiz Neves Abreu

Professor da Universidade Federal de Uberlândia

Rua Maria das Dores Dias, 941/303 38406-210 - Uberlândia - MG Brasil

jluiz@inhis.ufu.br
ABREU, Jean Luiz Neves. Educação sanitária e saúde pública em Minas Gerais na primeira metade do século XX. História, Ciências, Saúde Manguinhos, Rio de Janeiro, v.17, n.1, jan.mar. 2010, p.203-209.

\section{Resumo}

Apresenta resultados preliminares de estudo sobre a saúde pública em Minas Gerais, na primeira metade do século XX. Analisa, de maneira específica, a questão da educação sanitária e as estratégias de divulgação de preceitos de medicina entre a população mineira.

Palavras-chave: educação sanitária; saúde pública; Serviço Especial de Saúde Pública; Minas Gerais (Brasil).

\section{Abstract}

The article presents the preliminary results of the study on public health in the State of Minas Gerais during the first half of the twentieth century. It specifically analyzes the issue of sanitary education and the strategies for divulging medical precepts among the population of that state.

Keywords: sanitary education; public health; Special Public Health Service; Minas Gerais (Brazil). 
$\mathrm{N}$ esta nota de pesquisa apresentam-se resultados iniciais de pesquisa em andamento sobre o sanitarismo e a construção da saúde pública em Minas Gerais. ${ }^{1}$ Um dos propósitos do estudo é identificar os recursos mobilizados e os significados que a educação sanitária assumiu na primeira metade do século XX, período de reorganização dos serviços de saúde no estado. As fontes principais da pesquisa são as palestras da Rádio Inconfidência de Belo Horizonte e os artigos publicados no jornal oficial da imprensa do Estado, o Minas Gerais.

\section{Percursos da educação sanitária}

Um dos princípios do pensamento sanitarista no Brasil, nas primeiras décadas do século XX, foi o de educação para a saúde. Partia-se do pressuposto de que a ignorância era a causa principal das doenças (Hochman, 1988), tornando-se preciso promover a consciência sanitária da população com recursos modernos como projeção de filmes e transparências (Löwy, 2006, p.140-149).

Conforme demonstram pesquisas recentes, a educação sanitária foi um dos aspectos centrais das políticas de saúde implantadas em alguns estados brasileiros. Estudos sobre a saúde pública em São Paulo destacam a atuação do Instituto de Higiene e a articulação entre educação e saúde presente em suas diretrizes. Criado em 1918, em acordo com os princípios norte-americanos da Fundação Rockefeller, o órgão se constituiu em espaço para o desenvolvimento de estratégias para incutir hábitos de higiene entre a população e, principalmente, entre as crianças, por meio de propaganda e formação de educadoras sanitárias (Faria, 2007, p.153-169; Rocha, 2003). Segundo Helena Rocha (2003, p.218), "educação e propaganda figuraram como elementos indissociáveis de um programa de moralização que tinha, como um dos seus mais importantes pilares, a higienização da população".

Em pesquisa sobre a atuação dos médicos sanitaristas em Minas Gerais nas décadas de 1930 e 1940, Keila Auxiliadora Carvalho (2008) igualmente salientou o papel da educação sanitária e seus aspectos normatizadores. Essa educação visava a formação de uma "consciência sanitária coletiva" (p.106), tendo como alvo principal a escola e os professores, multiplicadores dos conselhos higiênicos. Para além do espaço escolar, a autora demonstra que o discurso dos médicos mineiros em defesa da higiene assumia aspectos nacionalistas e de regeneração do povo. Não obstante a relevância desse estudo, a autora pouco se detém no exame do papel da imprensa e do rádio como veículos disseminadores dos princípios higiênicos. Com efeito, levantamento realizado na Imprensa Oficial de Minas Gerais e na Fundação Ezequiel Dias evidenciou que, apesar de as escolas terem sido uns dos principais espaços para incutir hábitos de higiene ${ }^{2}$, a utilização da imprensa foi uma das principais estratégias de educação sanitária em Minas Gerais.

Desde os anos 1920, relatórios oficiais indicam que o governo estadual procurou intensificar a propaganda e educação higiênica por meio de palestras, distribuição de folhetos, artigos, notas de imprensa e filmes. O objetivo era "preparar o público para receber as medidas que fossem exigidas a bem da coletividade e entre os métodos de conservar a saúde e evitar as doenças" (Andrada, 1929, p.150). Diante do reconhecimento oficial das dificuldades enfrentadas, como a insuficiência das unidades sanitárias existentes, 
e a necessidade de dar maior amplitude ao serviço de educação sanitária, o decreto 69, de 20 de janeiro 1938, procurava estabelecer uma nova organização sanitária. A Inspetoria de Demografia e Educação Sanitária da Diretoria de Saúde Pública passou a se denominar Inspetoria de Propaganda e Educação Sanitária. Seu papel era o de "promover a educação sanitária do povo, por todos os meios modernos de divulgação: imprensa, palestras, folhetos, cartazes, exposições, filmes, radiofonia".

Ainda não foram localizados dados capazes de comprovar o incremento do serviço de propaganda após essa mudança. A hipótese é que meios de comunicação de massa imprensa e jornal - foram mobilizados para os propósitos da educação sanitária a partir de 1946. No levantamento inicial de fontes, encontra-se farto material a partir dessa data, o que coincide com a transformação da Inspetoria de Propaganda e Educação Sanitária em Divisão de Demografia e Educação Sanitária, com dois serviços separados: o Serviço de Demografia Sanitária, dedicado à estatística de nascimentos, casamentos, óbitos e dados sobre as causas de mortalidade, e o Serviço de Propaganda e Educação Sanitária (SPES).

Em 1947 o SPES promovia palestras de médicos e técnicos sanitários na Rádio Inconfidência. A maior parte dos palestrantes era composta de médicos sanitaristas que ocupavam postos importantes nos serviços de saúde do estado. Henrique Furtado Portugal foi um dos médicos que estiveram à frente dos programas de divulgação sanitária, tendo ocupado, em 1946, o posto de chefe do Serviço de Propaganda e Educação Sanitária. (Nota de falecimento, 25 jun. 1984). Marino Mendes Campos, por sua vez, era chefe do Departamento de Demografia e Educação Sanitária em 1952, responsável por organizar a publicação de diversas palestras em forma de livros. O perfil dos médicos que participaram dos programas da Rádio Inconfidência é um dos aspectos que merecem ser mais bem investigados.

Na Rádio eram promovidos alguns programas especiais, a exemplo do Programa de Medicina Social, às quintas-feiras. Entre 1949 e início de 1951, o médico Geraldo Portes foi o responsável por grande parte das palestras nesse programa, as quais eram publicadas no jornal Minas Gerais. Algumas delas foram selecionadas e publicadas em livros distribuídos às escolas. No volume a que tivemos acesso, o terceiro da série denominada Divulgação Sanitária, o médico Marino Mendes Campos (1952a) afirmava que as publicações tinham o propósito de "ampliar os trabalhos de divulgação e propaganda sanitárias, de caráter popular" e que os assuntos ali tratados eram de interesse de todos, principalmente das professoras do ensino primário. As escolas continuavam a ser, portanto, um importante foco dos médicos higienistas.

Outro meio de educação sanitária consistia em pequenos artigos publicados na seção Educação Sanitária do jornal Minas Gerais e distribuídos a outros diários da capital, como o Estado de Minas e Folha de Minas, além de jornais do interior. O rádio e o jornal atuaram conjuntamente na divulgação dos preceitos de saúde ao povo mineiro. Em março de 1949, por exemplo, a coluna Educação Sanitária publicava instruções sobre a profilaxia da sífilis, extraído de um folheto do doutor Amarílio Cabral Mata, chefe do Centro de Saúde de Teófilo Otoni. Na mesma página havia uma chamada sobre a palestra do doutor Hiram de Paula Ribeiro (9 mar. 1942, p.9), "A esquistosomose em Belo Horizonte e em Minas Gerais", a ser proferida na Rádio Inconfidência. Além de rádio e jornal, o Serviço contava com a distribuição de cartazes, folhetos e livros em instituições públicas e privadas, de 
ensino principalmente em escolas rurais dos municípios. Com o intuito de difundir as mensagens ao interior do estado, o critério adotado foi o geográfico e econômico, "com o que estão sendo beneficiados os pequenos, longínquos e sob vários aspectos, esquecidos municípios das fronteiras, do norte, nordeste, e noroeste do Estado" (Portugal, 2008c, p.238). O material distribuído provinha de várias fontes: do Serviço Nacional de Educação Sanitária e Serviço Especial de Saúde Pública e, em menor escala, da Escola Superior de Agricultura de Viçosa, Instituto Butantan e Instituto Pinheiros. Parcela do material impresso se destinava a cursos intensivos para professores rurais, iniciativa apoiada pela Secretaria de Educação (Portugal, 2008a).

Cabe notar que a utilização da imprensa e do rádio na promoção da educação sanitária em Minas Gerais seguia uma tendência nacional. O recurso a meios de comunicação de massa para difundir preceitos de higiene e saúde tais como cartilhas, rádio e filmes foram estratégias amplamente usadas no país, nas décadas de 1940 e 1950 (Campos, 2006, p.231232). Os artigos publicados no Minas Gerais e as palestras proferidas na Rádio Inconfidência nos dão uma ideia dos princípios que orientavam a educação sanitária naquele contexto.

\section{Princípios e temas da educação sanitária}

O médico sanitarista Henrique Furtado Portugal, em palestra proferida na Rádio Inconfidência em setembro de 1947, chamava a atenção para o fato de a educação sanitária ser o meio de se conseguir a "profilaxia verdadeira" e a "reeducação e a readaptação social para que existam menos sofredores, menor número de desajustados, para que a moral seja aprimorada, enfim para que a humanidade tenha uma vida mais humana" (Portugal, 2008d, p.240).

As ideias de profilaxia, educação e readaptação social são assuntos que permeiam várias das fontes analisadas. Algumas palestras tinham por finalidade apresentar inovações da medicina e dos métodos terapêuticos empregados no combate a doenças como tuberculose, malária e varíola. Nesse sentido, o médico Murilo Sales falou aos ouvintes sobre os "Métodos gerais de vacinação", enquanto Ênio Pinto Correa apresentou o tema "Vacinação antivariólica". Algumas traziam informações sobre etiologia e profilaxia de determinadas enfermidades, como por exemplo as palestras que comentavam a profilaxia do bócio endêmico, tema abordado por sanitaristas como Antônio Carneiro Maciel e Henrique Furtado Portugal. Outras visavam incutir hábitos de higiene e de saúde, a exemplo de "Higiene visual", proferida pelo doutor Casimiro Laborne Tavares, e "Alimentação do homem rural", de Mario Hugo Ladeira (Portugal, 2008a).

Os médicos se voltavam igualmente para assuntos que podiam converter em problemas sociais, como é o caso do alcoolismo, visto não só como prejudicial à saúde, mas também como responsável pelo aumento da criminalidade e diminuição da produtividade no trabalho (Bahia, 1952, p.19). A condenação de práticas consideradas perniciosas à saúde, como o consumo de bebidas alcoólicas, revela uma continuidade no discurso dos médicos mineiros, já que desde a década de 1930 se enfatizavam os prejuízos morais e econômicos daquele vício (Carvalho, 2008, p.118-120). 
Havia grande atenção à puericultura. Além dos serviços prestados nas escolas, várias palestras e textos publicados no Minas Gerais priorizavam a questão dos cuidados com as crianças. Em palestra pronunciada sobre a "Higiene e conforto do trabalhador", Henrique Furtado Portugal (2008b) não só tratou de questões inerentes ao trabalho, como também chamou a atenção para a relevância da puericultura, que tinha "por finalidade fazer vir ao mundo crianças sadias e mantê-las sadias" (p.227), sendo necessários cuidados pré-natais e após o nascimento. Na palestra, dirigida aos trabalhadores rurais, o médico incitou proprietários e pessoas cultas das zonas rurais a ensinar cuidados com o recém-nascido, como a vacinação necessária e a alimentação adequada.

O médico sanitarista Marino Mendes Campos (1952b) apresentou programa comentando a "Alimentação na idade escolar", no qual defendia a vigilância em torno do regime alimentar nas crianças, pois maus hábitos teriam influência na higidez de jovens e adultos. Forneceu várias informações sobre a qualidade nutricional dos alimentos e as vitaminas necessárias ao desenvolvimento infantil. Mário Hugo Ladeira (1952), secretário de Saúde e Assistência, insistia no argumento de que a educação da saúde deveria ter início na escola e responsabilizava igualmente as professoras pela tarefa. Propugnava que a educação sanitária seria capaz de mudar as características herdadas das crianças: "Promovendo práticas saudáveis e assistindo a ela quando for necessário, estaremos preparando uma geração forte e sadia para trabalhar para o engrandecimento desta Pátria" (p.8).

A infância e a adolescência traduziam-se em problemas sociais a serem enfrentados pela ciência. Segundo o doutor Geraldo Portes, que dedicou várias palestras ao assunto, cabia à medicina conhecer as condições físicas e orgânicas e as tendências de comportamento das crianças, com o intuito de atenuar "taras, vícios, má-formações, desvios, enfim, os defeitos físicos ou mentais" (Portes, 2 out. 1949). Os desvios de comportamento eram vistos como resultado do ambiente social e da constituição individual herdada. Uma das soluções para garantir a saúde física e moral residia no tratamento dos pais. O médico declarava que se "evitassem os casais que, eugenicamente, não deveriam formar-se, poder-se-ia conseguir que não aparecessem tantos casos anormais, física ou organicamente, assim como mentalmente".

Ao lado da puericultura, a questão do trabalho constituiu outro assunto privilegiado. Em suas falas, os médicos abordavam várias questões concernentes à saúde do trabalhador, tais como a necessidade de hábitos higiênicos, alimentação saudável e como evitar as enfermidades relacionadas ao trabalho. Geraldo Portes foi um dos que mais se debruçaram sobre o assunto em suas palestras. ${ }^{3}$ Em "O interesse social em cuidar do trabalhador" (Portes, 20 jan. 1949), enfatizava que cuidar da saúde daqueles que "promovem pelo seu labor, a grandeza da Pátria" era dever dos poderes públicos, formadores de opinião e de toda a coletividade, pois cada cidadão é uma célula do organismo social. O médico não se furtou também de comentar a respeito do trabalho feminino. Em artigo intitulado "Preservando o destino das gerações futuras" (Portes, 14 jan. 1949), condenava o fato de um número cada vez maior de mulheres incorporar-se ao mercado de trabalho. Citando a literatura médica acerca do tema, considerava que o trabalho feminino era inconveniente para a eugenia do povo, pois ele acarretaria em uma diminuição na natalidade entre as mulheres operárias, bem como em maior ocorrência de afecções genitais. 
A ênfase na puericultura e no trabalho, por parte dos médicos mineiros, remete a questões de saúde debatidas em âmbito nacional. A higiene infantil e a higidez futura das crianças eram argumentos eugênicos que prevaleceram durante o Estado Novo, contexto em que houve também uma significativa atenção à puericultura como instrumento de incorporação das massas ao Estado (Stepan, 2004, p.372-377). Da mesma forma, desde a década de 1930 a infortunística, como área médica crescentemente especializada, destinavase às questões da saúde do trabalhador, orientada para identificar as predisposições biológicas dos operários, bem como a adequação física e psíquica às condições de trabalho (Ferla, 2005). Nesse contexto, o Estado passava a se preocupar cada vez mais com a saúde física e adaptação psíquica do trabalhador (Gomes, 1982).

\section{Considerações finais}

A análise preliminar das fontes permite relacioná-las com temas que eram discutidos em âmbito nacional, a exemplo da preocupação com a higiene, a puericultura e a saúde do trabalhador. Conforme indicam as palestras analisadas, a educação sanitária era um meio de contornar problemas que impediriam o futuro das gerações e a grandeza da pátria. Dessa forma, a educação tornava-se o meio mais eficaz de criar hábitos saudáveis e diminuir as enfermidades que repercutiam negativamente na transformação da sociedade mineira.

No decorrer da pesquisa pretende-se levantar outros tipos de materiais utilizados na propaganda sanitária em Minas Gerais, como cartazes e livros. Outro aspecto a ser analisado é o conteúdo dos pequenos artigos de Divulgação Sanitária publicados nos jornais. Dessa maneira, esperamos que a pesquisa contribua para a compreensão dos significados que a educação pela saúde assumiu no estado.

\section{NOTAS}

${ }^{1}$ A pesquisa conta com o apoio da Fundação de Amparo à Pesquisa do Estado de Minas Gerais (Fapemig).

${ }^{2}$ Em fins da década de 1920 foram organizados serviços de higiene e profilaxia escolar em vários municípios mineiros, como Juiz de Fora, Uberaba e Poços de Caldas. Com o propósito de auxiliar o trabalho dos médicos que visitavam as escolas, criou-se um corpo de enfermeiras escolares, cuja função era incutir nas crianças hábitos de higiene e fiscalizar a prática dos mesmos, preencher as fichas escolares dos alunos, tomar medidas profiláticas para as 'moléstias contagiosas' e apresentar as crianças doentes ao médico escolar, por ocasião de sua visita (Vianna, 1926).

3 Das palestras de Geraldo Portes dedicadas ao tema, podem-se citar: "Tuberculose, doença profissional" (Portes, 26 jan. de 1949) e "O Brasil e o próximo Congresso Pan-Americano de medicina do trabalho" (Portes, 11 dez. 1949).

\section{REFERÊNCIAS}

ANDRADA, Antonio Carlos Ribeiro de. Mensagem do presidente de Estado Antonio Carlos Ribeiro de Andrada ao Congresso Mineiro. Belo Horizonte: Imprensa Oficial do Estado de Minas Gerais. 1929.

BAHIA, A. Valadares.

Alcoolismo. In: Divulgação Sanitária (palestras

na Rádio Inconfidência). Belo Horizonte:
Secretaria de Saúde e Assistência do Estado de Minas Gerais. p.18-20. 1952.

CAMPOS, André Luiz Veira de.

Políticas internacionais de saúde na Era Vargas: o Serviço Especial de Saúde Pública, 1942-1960. Rio de Janeiro: Editora Fiocruz. 2006. 
CAMPOS, Marino Mendes.

Apresentação. In: Divulgação sanitária (palestras na Rádio Inconfidência). Belo Horizonte: Secretaria de Saúde e Assistência do Estado de Minas Gerais. 1952a.

CAMPOS, Marino Mendes.

Alimentação na idade escolar. In: Divulgação Sanitária (palestras na Rádio Inconfidência). Belo Horizonte: Secretaria de Saúde e Assistência do Estado de Minas Gerais. p.60-64. 1952b.

CARVALHO, Keila Auxiliadora.

A saúde pelo progresso: medicina e saúde pública em Minas Gerais. Dissertação (Mestrado em História) - Universidade Federal de Juiz de Fora, Juiz de Fora. 2008.

FARIA, Lina.

Saúde e política: a Fundação Rockefeller e seus parceiros em São Paulo. Rio de Janeiro: Editora Fiocruz. 2007.

FERLA, Luís.

O trabalho como objeto médico-legal em São Paulo dos anos 30. Asclépio, Madrid, v.57, n.1, p.237-26, 2005.

GOMES, Ângela de Castro.

A construção do homem novo: o trabalhador brasileiro. In: Oliveira, Lúcia Lippi; Velloso, Mônica Pimenta; Gomes, Ângela de Castro. Estado Novo: ideologia e poder. Rio de Janeiro: Jorge Zahar. p.151-166. 1982.

HOCHMAN, Gilberto.

Logo ali, no final da avenida: os sertões redefinidos pelo movimento sanitarista da Primeira República. História, Ciências, Saúde Manguinhos, Rio de Janeiro, Rio de Janeiro, v.5, supl., p.217-235. 1998

LADEIRA, Mário Hugo.

Educação da saúde na escola. In: Divulgação Sanitária (palestras na Rádio Inconfidência). Belo Horizonte: Secretaria de Saúde e Assistência do Estado de Minas Gerais. p.6-8. 1952.

LÖWY, Ilana.

Vírus, mosquitos e modernidade: a febre amarela no Brasil entre ciência e política. Rio de Janeiro: Editora Fiocruz. 2006.

\section{NOTA DE FALECIMENTO.}

Estado de Minas, Belo Horizonte. 25 jun. 1984.

PORTES, Geraldo.

O Brasil e o próximo Congresso Pan-Americano de medicina do trabalho. Minas Gerais, Belo Horizonte, p.5. 11 dez. 1949.

PORTES, Geraldo.

Infância em perigo moral como problema social. Minas Gerais, Belo Horizonte, p.8. 2 out. 1949.

\section{PORTES, Geraldo.}

Tuberculose, doença profissional. Minas Gerais, Belo Horizonte, p.12. 26 jan. de 1949.
PORTES, Geraldo.

O interesse social em cuidar do trabalhador. Minas Gerais, Belo Horizonte, p.11. 20 jan. 1949.

PORTES, Geraldo.

Preservando o destino das gerações futuras. Minas Gerais, Belo Horizonte, p.11. 14 jan. 1949.

PORTUGAL, Henrique Furtado.

A propaganda e o serviço de saúde em torno das atividades do SPES em 1948. In: Saliba, Ana Maria Portugal Maia (Org.). A saúde pública nas serras, altiplanos, sertões e gerais: textos de Henrique Furtado Portugal. Belo Horizonte: s.n. p.262-265. Palestra proferida na Rádio Inconfidência, em 18 de janeiro de 1949. 2008a.

PORTUGAL, Henrique Furtado.

Higiene e conforto do trabalhador. In: Saliba, Ana Maria Portugal Maia (Org.). A saúde pública nas serras, altiplanos, sertões e gerais: textos de Henrique Furtado Portugal. Belo Horizonte: s.n. p.220-233. Palestra proferida na Rádio Inconfidência, em 19 de abril de 1947. 2008b.

PORTUGAL, Henrique Furtado.

Atividades de um ano da Divisão de Demografia e Educação Sanitária. In: Saliba, Ana Maria Portugal Maia (Org.). A saúde pública nas serras, altiplanos, sertões e gerais: textos de Henrique Furtado Portugal. Belo Horizonte: s.n. p.234-238. Palestra proferida na Rádio Inconfidência em 17 de agosto de 1947. 2008c.

PORTUGAL, Henrique Furtado. Conceito médico-social das doenças venéreas. In: Saliba, Ana Maria Portugal Maia (Org.). A saúde pública nas serras, altiplanos, sertões e gerais: textos de Henrique Furtado Portugal. Belo Horizonte: s.n. Palestra proferida na Rádio Inconfidência em 27 set. 1947. 2008d

RIBEIRO, Hiram de Paula.

A esquitosomose em Belo Horizonte e em Minas Gerais. Minas Gerais, Belo Horizonte, Educação Sanitária, p.9. 9 mar. 1942.

ROCHA, Heloísa Helena Pimenta. A higienização dos costumes: educação escolar e saúde no projeto do Instituto de Hygiene de São Paulo (1918-1925). Campinas: Mercado das Letras. 2003.

STEPAN, Nancy Leys.

Eugenia no Brasil, 1917-1940. In: Hochman, Gilberto; Armus, Diego (Org.). Cuidar, controlar, curar: ensaios históricos sobre saúde e doença na América Latina e Caribe. Rio de Janeiro: Editora Fiocruz. p.331-391. 2004.

VIANNA, Fernando de Mello. Mensagem do presidente Fernando de Mello Vianna. Belo Horizonte: Imprensa Oficial do Estado de Minas Gerais, 1926. 